\title{
RESEARCH PAPER \\ ASSESSING THE EFFICACY OF DYES EXTRACTED FROM SOME LOCAL PLANTS FOR COLOURING COTTON FABRICS
}

\author{
N. A. Opoku-Asare, O. Korankye and K. Adu Baah \\ Department of Art Education, KNUST, Kumasi \\ Corresponding author:naopoku-asare.art@knust.edu.gh/naopokuasare@gmail.com
}

\begin{abstract}
Natural dyes from plant, animal and mineral sources have been used for centuries across the world. This study however, describes art studio quasi experiments conducted with the leaves, barks, seeds, roots, and fruit pods of 21 local plants to ascertain their potential for yielding dyes that would colour cotton fabrics and withstand frequent laundering. The methodology involved boiling the crushed leaf samples or chopped woody samples for between 15 and 30 minutes, draining the liquor into a plastic bowl, immersing the test cotton fabric and dyeing it hot or cold. With the exception of Adansonia digitata dye which was too weak to stain the fabric and Bixa orellana dye which was not colourfast and faded beyond recognition within six weeks, the other 19 plants yielded highly coloured, light- and wash-fast dyes of varying strengths, suggesting their feasibility for teaching basic skills in tie-dyeing, batik, watercolour painting and printmaking, which constitute integral aspects of the Visual Arts curriculum in Ghana. The study identified sodium carbonate as an effective mordant for improving the colour, strength and fastness of the brown Bridelia ferruginea dye which is the backbone of the indigenous textiles industry.
\end{abstract}

Keywords: Natural dye, local plants, colour work, visual arts curriculum, Ghana

\section{INTRODUCTION}

Colour in textiles is one of the most significant factors in the appeal and marketability of textile products mainly because consumers generally expect aesthetically pleasing colours, prints, and colour permanence (Kadolph, 2007; Elsasser, 2007). Colour in textiles is produced by dyeing, printing or painting (Harris, 1995). Dyeing processes may be used either to colour fibres and yarns before they are made into cloth or to colour and decorate the fabric itself (World Book Incorporated, 2001). Dyes may be applied as a solution or paste. When a textile fabric, fibre or yarn is placed in the dye bath, the material absorbs the molecules of the dye and assumes the colour of the dye. Any excess dye that remains on the outside of the fibre can bleed or become sensitive to surface abrasion. To be usable in colouring fabrics, Tortora and Collier (1997) posit that a dye must be highly 
coloured; colourfast or resistant to colour change or loss during use and care; and be soluble or capable of being made soluble in water or other medium in which they are applied, or they must themselves be molecularly dispersible into the fibres of the fabric. Dyed textiles however, vary in their ability to hold colour so mordants such as salt, alum and iron are sometimes used to regulate absorption of the dye into the fibre so that the fabric can hold its colour under normal use, laundering or exposure to sunlight (World Book Incorporated, 2001). A mordant also has the ability of changing the colour of dyes as well as improving the colourfastness of dyed fabrics (Tortora and Collier, 1997).

\section{Plant dyes}

Characteristically, most plant dyes initially appear vivid with colourful effects yet they are not substantive, and have little or no colouring power in themselves except when used in conjunction with mordants, except for plants which contain a lot of tannin (Aimson, 1999). Most plant dyes are derived from the seeds, fruit pods, berries, leaves, roots and barks of trees (World Book Incorporated, 2001). The most common and well-known plant dye is indigo, a dark blue dye that comes from the leaves of the Indigofera tinctoria, a plant which grows chiefly in India and has been used widely by Yoruba cloth dyers of Nigeria as a dye for centuries. Indigo is known in China, Japan and many Asian countries and to ancient civilizations in Mesopotamia, Egypt, Greece, Rome, Britain and Peru. This extremely important source of blue dye is still very popular in making special types of designs for modern fabrics such as denim (Yang and Narasin, 1989). Henna, an orange-brown dye made from a shrub of North Africa and the Middle East, is used to dye leather and sometimes human hair (World Book Incorporated, 2001).

The madder plant (Rubia tinctorum) is cited as the source of the brilliant red permanent dye Turkey Red that was very well known in 19th century domestic history. Also known as Adri- anople Red, Turkey Red was used for many fabrics including linen and silk. The wild madder (Rubia peregrina) also provides a subtler, rose-pink dye while the roots of some other species of the madder family produce a whole range of reds (Aimson, 1999). The woad tree (Isatis tinctoria) is another important source of the blue dyestuff that was used for over 2000 years in Europe up to the end of the Middle Ages (Collier and Tortora, 2001). Bright black and brown dyes extracted from the pulp of the logwood in Central America, Mexico and the West Indies were also used for dyeing silk, cotton and fur (Aimson, 1999). In Ghana, dark brown, black and red dyes derived from mangroves, Bridelia ferruginea, Bombax brevicuspe, Sorghum vulgare and other dyeyielding plant species have been used for dyeing cloth, straw, fishing nets, food, skein and leather for centuries (Irvine, 1961; Willis, 1998; Lugutuah, 2004). Other sources of natural dyes were yellow from the stigmas of the saffron plant, the scarlet red Cochineal obtained from an insect native to Mexico, and purple dyes extracted from shellfish (Purple fish) that were found near Tyre on the Mediterranean coast (Microsoft Encarta Encyclopedia, 2003).

Gebelein (1997) estimates that about 8,500 purple fish were crushed to produce one gram of purple dye which made it so expensive that only kings and the wealthy could afford to use them while poorer people wore white or drab colours made from vegetable dyes. According to Gebelein, Chemistry changed radically the history of dyeing when in 1856, William Perkin, an English chemist working in London, made an accidental discovery of a purple dye called Mauve while trying to synthesize quinine by reacting aniline sulphate with an oxidizing agent. Mauve was found to dye silk and although it was not particularly fast, it became popular. This first synthetic dye influenced the development of the synthetic dye industry to the extent that today, the textiles industry uses synthetic dyes almost entirely because they are soluble, more colourful, they hold their colour 
better, and cost less to produce than plant dyes (Gebelein, 1997; World Book Incorporated, 2001; Microsoft Encarta Encyclopedia, 2003). This study essentially sought to find alternative plant dyes and pigments that could be utilized by Visual Arts teachers to help their students acquire and master skills in fabric decoration, printmaking and watercolour painting through copious class exercises so they could transfer those skills to the use of conventional poster and water colours, and synthetic dyes for examination purposes.

\section{MATERIALS AND METHODS}

Samples of the 21 plants studied were collected through assisted visits from a variety of sources: the Kwame Nkrumah University of Science and Technology botanic gardens and the University of Cape Coast arboretum because they hold documented collections of living plants for scientific research, conservation, aesthetic appreciation and education (Willis et al. 2004 as cited in Anning et al., 2008); Ntonso in Ashanti Region, the centre of the indigenous Ghanaian textiles industry; Amanten, Atebubu and Nkoransa in Brong Ahafo Region and Damongo in the Northern Region where most of the selected plants characteristically grow (Irvine, 1961). Plant samples collected for the study comprised roots, barks, fruit pods, leaves and seeds which are the sources of most plant dyes (World Book Incorporated, 2001).

\section{Collection and treatment of samples}

The tree bark, seed, root, fruit pod and leaf samples used in the study were collected from the different locations during the dry season. Plants described by Irvine (1961) and certified by the resource persons as toxic were excluded from the study. Table 1 lists the plants studied and the parts used. All the samples collected were air-dried to prevent fungi growth and then sealed in individually labeled, transparent plastic bags for easy identification. The leaf samples were either used soon after collecting them or refrigerated in labeled plastic bags prior to use.
As also indicated in Table 1, the sampled plants were identified by their botanic names for convenient reference and where possible, the local names given by the resource persons were also provided. The vernacular names of the plants are indicated in Twi except where only $G a(\mathrm{~g})$ or Hausa (h) names were found. Known English names were used where no local names were found for any of the plants.

\section{Dye extraction procedure}

Dyes produced from natural sources are processed mainly by mechanical ways like grinding, crushing, or steeping in water. Root and bark samples used in the study were steeped overnight, pre-heated gently and gradually brought to boil separately for 30 minutes or more. After boiling, each dye was poured out of its container into another labeled container, in which the test fabrics were immersed and left to absorb the dye. The fresh leaf samples were crushed to pulp, mixed with water, strained through a fine plastic sieve and simmered gently on low heat for 15 minutes only or until the onset of colour loss.

\section{Test Dyeing}

Each dye solution was tested for its potential for direct dyeing, fabric affinity and the effect of temperature changes on the colour and fastness of each dye. Hot and cold dyeing was therefore adopted, using both bleached and unbleached cotton fabric to allow for easy visual evaluation and analysis of colour variations. The procedure for hot dyeing involved immersing test pieces in the dye solution soon after the boiled mixture had been strained; cold dyeing of same samples occurred after the strained dye solution had been allowed to cool to room temperature. Test fabrics were dried flat on sheets of newsprint spread out for the purpose. Samples of the dyes and pigments were kept in labeled glass specimen bottles and observed over a six-week period to ascertain their natural preservative properties and possible colour change over time. Table 2 indicates the plants that yielded substantive dyes. Tables $3-5$ also show the range of colours the plant samples yielded. 
54 Opoku-Asare et al.

Table 1 - Plants studied

\begin{tabular}{|c|c|c|}
\hline Botanical name & Vernacular name & Part(s) used \\
\hline Adansonia digitata & Dade $\varepsilon$ & Bark \\
\hline Anogeissus leiocarpus & Kanne & Leaves \\
\hline Alchornea cordifolia & Gyama & Fruit, seeds \\
\hline Anacardium occidentalis & Atea, Cashew & Leaves \\
\hline Azadiracha indica & Dua gyeene ;Neem/Nim & Bark, leaves \\
\hline Bixa orellana & Abrofo gyama & Seeds \\
\hline Bombax brevicuspe & Kuntunkuni & Bark \\
\hline Bombax buonopozense & 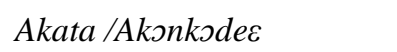 & Bark \\
\hline Bridelia ferruginea & Badec & Bark \\
\hline Cassia occidentalis & Nkwadaa nkwadaa brodee & Pod husk \\
\hline Griffonia simplicifolia & Kagya & Leaves \\
\hline Hymenocardia acida & Sabrakye /Dua kokso & Bark \\
\hline Khaya senegalensis & Mahogany & Bark \\
\hline Lagernaria vulgaris & Duantoa / koradua & Leaves \\
\hline Lawsonia inermis & Leele $(h)$ & Leaves \\
\hline Mangifera indica & Mango & Bark, leaves \\
\hline Morinda lucida & Buronya dua & Root wood \\
\hline Parkia biglobosa & Dawadawa $(h)$ & Pod husk \\
\hline Psidium guajava & Guaa & Bark, leaves \\
\hline Tamarindus indica & Blofo yoyitso $(g)$ & Bark \\
\hline Tectona grandis & Teak & Teak \\
\hline
\end{tabular}

Table 2 - Plants that yielded substantive dyes

\begin{tabular}{lc}
\hline \multicolumn{1}{c}{ Plant } & Colour of Dye \\
\hline Bombax breviscupe & Brown \\
Lawsonia inermis & Red \\
Cassia occidentalis & Brown/Black \\
Morinda lucida & Yellow / Red \\
Anogeissus leiocarpus & Yellow \\
Tamarindus indica & Brown / Red \\
Alchornea cordifolia & Brown/Black \\
Anacardium occidentalis & Black \\
Bixa orellana & Red/Yellow \\
Bridelia ferruginea & Brown \\
Khaya senegalensis & Brown \\
Mangifera indica & Yellow \\
Psidium guajava & Grey / Black \\
Tectona grandis & Red \\
Griffonia simplicifonia & Brown \\
\hline
\end{tabular}


Efficacy of dyes extracted from local plants... 55

Plates 1-6 show the most outstanding of the substantive dyes obtained from the plant samples.

\section{Applying Mordants}

To improve the colour fastness of some fabrics, dyers add mordants to dye baths to "fix" the colour firmly in the fibres and prevent the dye from dissolving easily. The dye alone might wash out but the compound formed by the dye and the mordant will not, so the colour lasts long in the fibre or fabric. Thus, mordants control the colours of dyes and make them permanent. However, mordants can also change the colour of some plant dyes depending on the quantity and type used. Mordanting can be done before, during and after dyeing (Tortora and Collier, 1997).

Table 3 - Shades of red dye

\begin{tabular}{lcc}
\hline Plant & Part of sample used & State of sample \\
\hline Khaya senegalensis & Inner bark & Fresh \\
Tamarindus indica & Inner bark & Dry \\
+ Khaya senegalensis & & \\
Cassia occidentalis & & Fresh \\
Bridelia ferruginea & Fruit pod & Dry \\
Adansonia digitata & Inner bark & Dry \\
Bombax brevicuspe & Inner bark & Dry \\
Lawsonia inermis & Inner bark & Fresh \\
\hline
\end{tabular}

Table 4 - Shades of brown dye

\begin{tabular}{lcc}
\hline Plant & Part of sample used & State of sample \\
\hline Bixa orellana & Seeds & Dry \\
Anogeissus leiocarpus & Tender leaves & Fresh \\
Morinda lucida & Root wood & Fresh \\
Mangifera indica & Tender leaves & Fresh \\
Psidium guava & Tender leaves & Fresh \\
\hline
\end{tabular}

Table 5 - Shades of yellow dye

\begin{tabular}{lcc}
\hline Plant & Part of sample used & State of sample \\
\hline Cassia occidentalis & Fruit pods & Dry \\
Alchornea cordifolia & Seeds & Dry \\
Psidium guava & Leaves & Dry \\
Anacardium occidentalis & Leaves & Dry \\
\hline
\end{tabular}




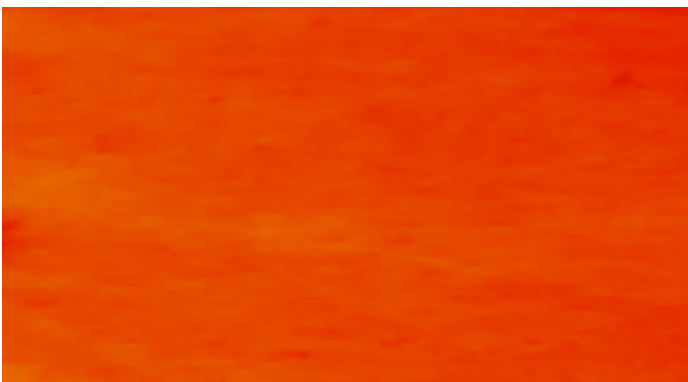

Plate 1: Red from Bixa orellana seeds

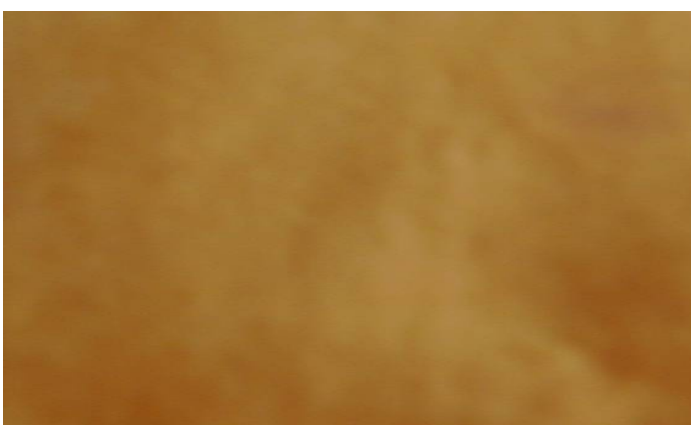

Plate 2: Brown from Khaya senegalensis inner bark

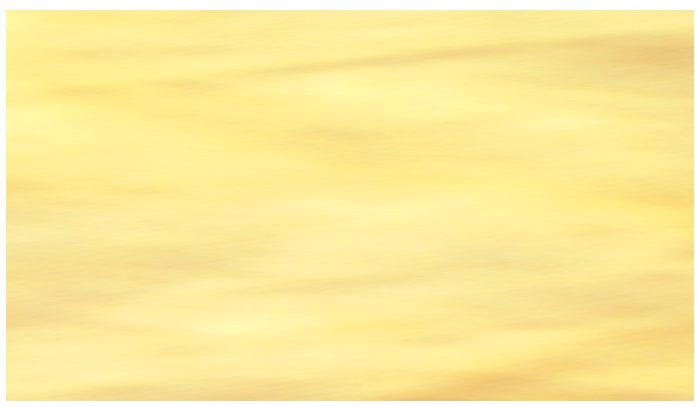

Plate 3: Yellow from tender Anogeissus leiocarpus leaves

Mordants that were used in this basic art studio quasi experimental project (not a standard texttiles laboratory) were cooking salt, alum and soda ash (sodium carbonate), which are used

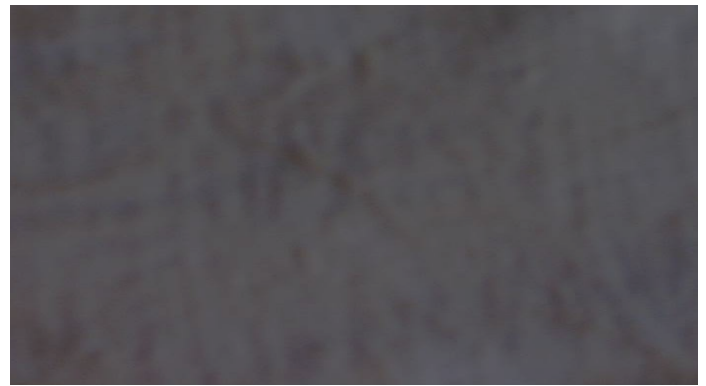

Plate 4: Black from dry Anacardium occidentalis leaves

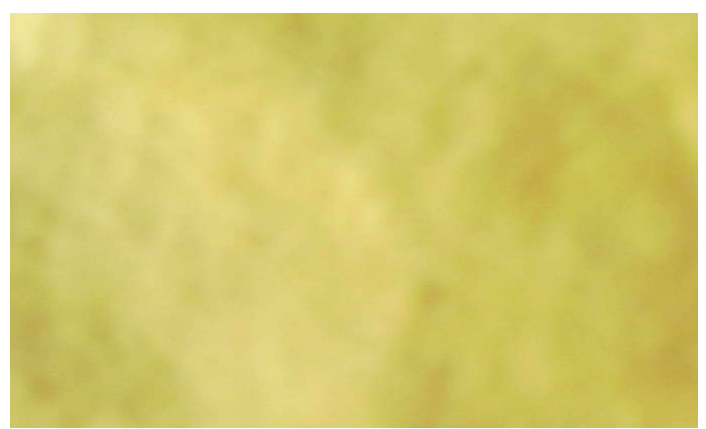

Plate 5: Green from tender Azadiracha indica leaves

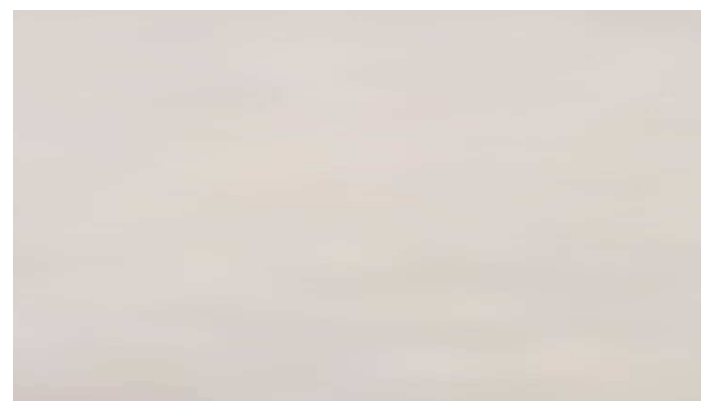

Plate 6: Blue from tender Mangifera indica leaves

with synthetic dyes in batik and tie-dye production (Asmah, 2004). Sodium carbonate was adapted purposely to ascertain its suitability for plant dyes. These mordants were applied to 
assess their individual effects on particular dyes; possible variations in fabric affinity; possible modifying effects on weak and strong dyes; and the potential of each substance for improving the fastness of the dyes derived from the plants.

In this project, mordants were applied in two ways: 1) dissolving the substance in the dye solution before immersing the fabric in the case of direct dyeing; and 2) dissolving the mordant in water and immersing the fabric in the solution before dyeing it. In the experiments, dyed test fabrics that came out too pale were dyed again or mordanted before re-dyeing. Such test fabrics were discarded where re-dyeing or mordanting had no significant effects on them as was the case with the unbleached cotton samples.

\section{Wash and Light Fastness Tests}

Wash and light fastness tests were conducted to ascertain whether the identified dyes would withstand washing and drying when used to colour everyday clothes. The test procedure involved washing one each of the wet and dry test fabrics dyed with the root and bark dyes and two pieces of test fabrics dyed with the leaf dyes with locally produced Keysoap and rinsing them in clean tap water. The wet and dry test samples were separated, pinned on the studio wall and observed daily for six weeks. One set of the test fabrics was exposed to direct sunlight and the other set to indirect sunlight.

\section{DISCUSSION OF MAIN FINDINGS}

With the exception of Adansonia digitata solution which was too weak to stain the test fabrics and was therefore discarded at the first opportunity, dyes obtained from the other 20 plants (Table 2) were strong enough for direct dyeing on cotton fabric. The dyes however, varied in strength and colour. The colour of Anogeissus leiocarpus, Mangifera indica, Psidium guajava and fresh Morinda lucida rootwood dyes were found to lack brilliance and so required application of mordants. The hot and cold dyeing strategy adopted had no significant effects on ab- sorption quality but it was noticed that the unbleached cotton test fabrics were simply not absorbent in view of its sizing and had to go through bleaching with Parozone bleach with the view of improving its affinity to the dyes. Bleaching the test fabrics before dyeing was inefficient; it only made the fabric whiter without removing the sizing. The treatment was therefore abandoned because it was unsuccessful and it took more time off the dyeing schedule without adding any significant value to the tests. The unbleached cotton test fabrics were therefore discarded.

The test results showed that boiling the leaf samples for more than 15 minutes caused significant colour loss to both sample and its dye as indicated by Azu (1985) and AkuamoahBoateng (1989). The short extracting time made it difficult to store and observe samples of dyes obtained from the leaf samples as they began deteriorating and giving off offensive odour after three days unlike the bark and root samples that had to be boiled for 30 minutes or more to obtain the richest colour and strength of dyes (Korankye, 2010). It was also found that adding a few drops of lime juice significantly improved the stability and shelf life of the dyes derived from leaves but this could not prolong their shelf life beyond one week after which the samples were discarded. The root and bark dye samples generally remained stable throughout the six-week observation period; adding salt to the solution significantly improved their stable shelf life which suggests the feasibility of salt and lime juice as basic preservatives for plant dyes.

\section{Effect of Mordants Used}

Mordants used in the experiment had the effect of deepening or changing the original colour of the dyes. For example, the dye obtained from fresh, tender leaves of Anogeissus leiocarpus changed from dull yellow to brilliant yellow with alum mordant while the pale yellowishgreen dye obtained from fresh Mangifera indica leaves turned deep yellow with the alum mordant. The brilliant yellow Morinda lucida 
rootwood dye turned brilliant red with soda ash while the pale brown Khaya senegalensis bark dye turned darker and stronger with alum as well as soda ash. Whereas alum, salt and soda ash had no observable effects on the black Cassia occidentalis dye, the brown Bridelia ferruginea dye assumed a strong, darker shade with improved fastness with the soda ash mordant. The effect of soda ash on the Bridelia ferruginea dye, which is the main source of dye used by the indigenous textiles dyeing and printing industry in Ghana (Willis, 1998), is particularly significant in terms of its brilliance, richness of colour, wash and light fastness, and improved affinity for cotton fabric. Soda ash therefore offers hope for improving the traditional dark brown Brisi and black Kuntunkuni funeral cloths produced in the Eastern, Ashanti and Brong Ahafo Regions of Ghana.

Washing the test fabrics dyed in Bixa orellana and Tectona grandis dyes with Keysoap significantly made them paler than their original brilliant orange and bluish colours respectively but washing had no significant effect on the dyes obtained from Anogeissus leiocarpus, Morinda lucida and Bombax brevicuspe. Exposing the Bixa orellana and Tectona grandis dyed test fabrics to direct sunlight resulted in very significant colour deterioration inn both, suggesting their unsuitability for dyeing everyday clothes if mordants are not used to improve their colourfastness. On the other hand, Anogeissus leiocarpus, Morinda lucida, Cassia occidentalis, Khaya senegalensis, Psidium guajava and Bombax brevicuspe dyes showed no change in colour, indicating their ability to withstand laundering in the prevailing hot and humid weather conditions in Ghana. This suggests their viability as dyes for colouring everyday clothes.

After the wash fastness test, two long strips were torn off each large piece of fabric dyed with Anogeissus leiocarpus, Morinda lucida, Cassia occidentalis, Khaya senegalensis, Psidium guajava and Bombax brevicuspe dyes and pinned on a portion of the studio wall, one in direct sunlight and the other in indirect sunlight. After six weeks of daily observation, the exposed test fabrics were compared with the strips of unexposed fabric to ascertain any colour differences. It was realized that the Bombax brevicuspe, Cassia occidentalis and Alchornea cordifolia test samples that were exposed to direct sunlight showed slight colour changes but no change occurred in the colour of samples that were shaded from direct sunlight. This suggests the suitability of these dyes for colouring everyday clothes.

The most significant change of colour occurred in the Bixa orellana dyed fabric. The brilliant orange dye obtained from the dry seeds went through considerable colour change over the six -week period, finally turning to a pale, dull brown that bore no semblance to the original bright orange colour obtained with the soda ash mordant. This result differed markedly from what was observed when the dry Bixa orellana seeds were used as crayons to draw pictures directly on cartridge paper and exposing the drawings to direct sunlight. In direct contrast to the colour change in the dyed fabric sample, sunlight had no significant effect on the redorange drawing on paper over the six-week period. Further research therefore needs to be done on the Bixa orellana dye to find the best mordant to improve its stability and fastness to light in order to render this beautiful brilliant orange dye suitable for colouring everyday clothes that require frequent washing and drying. Perhaps, it is this unstable characteristic of the Bixa orellana dye that accounts for its use as a food colourant (World Book Incorporated, 2001).

\section{CONCLUSION}

Although this study was conducted in a basic Art studio with no conventional laboratory equipment for processing the plant samples, the study is significant for enriching Visual Arts education at the different levels. It is also relevant for developing creativity in non-formal educational settings. The extensive nature of plant dyes however, demands in-depth research 
and chemical analysis in order to understand the properties of the identified dyes, their reaction with particular mordants, and how the liquid dyes could be processed into drawing and printing inks, watercolour and fabric paints, and powder colours for sustained use. Nonetheless, the results of this investigation holds promise for expanding the raw material base of the Visual Arts curricula followed in Senior High Schools, the Polytechnics and universities as well as innovating the teaching and learning of Creative Arts and Basic Design and Technology in Primary and Junior High schools respectively.

\section{REFERENCES}

Aimson, K. (1999). Using Natural Plant Dyes. Beltane Publishers. London.

Akuamoah-Boateng, W. A. (1989). 'Materials for Teaching Batik and Tie-Dye in Secondary Schools'. MA Thesis. Department of Art Education. University of Science and Technology. Ghana.

Anning, A. K, Akyeampong, S., AddoFordjour, P., Anti, K. K., Kwarteng, A. and Tettey, Y. F. (2008). Floristic Composition and Vegetation Structure of the KNUST Botanic Garden. Ghana. Journal of Science and Technology. 28 (3) :103-116.

Asmah, A. E. (2004). 'A Manual on Batik and Tie-and-Dye for Teachers'. MPhil Thesis. Department of Art Education. University of Science and Technology. Ghana.

Azu, B. (1985). 'Extraction and Application of Dyes from Vegetable Matter'. BA Thesis. Department of Painting, Sculpture and Rural Art. University of Science and Technology. Ghana.

Elsasser, V. H. (2005). Textiles Concepts and
Principles. $2^{\text {nd }}$ Ed. Fairchild Publications, Inc. NewYork.

Gebelein, C. G. (1997). Chemistry and Our World. Wm. C. Brown Publishers. Dubuque. Indiana.

Harris, J. (1995). 5000 Years of Textiles. British Museum Press. London.

Irvine, F. R. (1961).Woody Plants of Ghana. Oxford University Press, Oxford.

Kadolph, S. J. (2007). Textiles. $10^{\text {th }}$ Ed. Pearson Prentice Hall, Boston.

Korankye, O. (2010). 'Extraction and Application of Plant Dyes to Serve as Colourants for Food and Textiles'. MPhil Thesis. Department of General Art Studies. Kwame Nkrumah University of Science and Technology. Ghana.

Lugutuah, V. (2004). 'The Effect of Different Additives on the Sensory Qualities of Waakye'. MPhil Thesis. Department of Nutrition and Food Science. University of Ghana.

Microsoft Corporation (1992-2002). Microsoft ${ }^{\circledR}$ Encarta ${ }^{\circledR}$ Encyclopedia 2003.

Tortora, P. G. and Collier, J. (1997). “Adding Color to Textiles" in Understanding Textiles. Merrill Prentice-Hall Inc. Upper Saddle River.

Willis, B. W. (1998). The Adinkra Dictionary. The Pyramid Complex. Washington D.C.

World Book Incorporated (2001). The World Book Encyclopaedia Vol. 5 Chicago.

Yang, S. and Narasin, M. R. (1989). Textile Art of Japan, Shufunomoto Japan Publications. 